\title{
Kidneys in 5-year-old preterm-born children: a longitudinal cohort monitoring of renal function
}

\author{
Rachel Vieux ${ }^{1}$, Marion Gerard ${ }^{2}$, Audrey Roussel ${ }^{3}$, Aïssata Sow ${ }^{2}$, Amelie Gatin $^{4}$, Francis Guillemin ${ }^{1}$ and Jean-Michel Hascoet ${ }^{2}$
}

BACKGROUND: Being aware of the impact of low birth weight on late-onset hypertension, our aim was to describe systolic blood pressure (sBP) and renal function in 3-5-yearold preterm-born children and to determine which perinatal factors or childhood factors were associated with an altered renal function at 5 years in these children.

METHODS: This was a prospective longitudinal cohort study of children born at 27-31 weeks of gestation and included at birth and examined at 3,4, and 5 years of age. The primary outcome was renal function at 5 years: BP, estimated glomerular filtration rate, and albuminuria.

RESULTS: One hundred and sixty five children were examined, of whom 93 (56.4\%) were male. Gestational age was 29.2 \pm 1.4 weeks and birth weight was $1,217 \pm 331 \mathrm{~g}$. Overall, 25\% children had sBP $\geq 90$ th percentile at age 3 and 4 years and $11 \%$ at 5 years. In multivariate analysis, sBP $\geq 90$ th percentile at 5 years was associated with the use of antenatal steroids $(O R=0.19(0.05 ; 0.65))$. There was a significant association between protein intake on day 28 and SBP at 5 years $(\beta=2.1 \pm 1.0, P=0.03)$. Glomerular filtration rate at 5 years was significantly decreased in case of hyaline membrane disease or necrotizing enterocolitis. High urine albumin was not predictable from one year to another.

CONCLUSION: In preterm-born children, sBP was often high and neonatal protein intake was associated with increased blood pressure during childhood.

O rgan function in low birth weight (LBW) or pretermborn adults is marked by perinatal imprinting $(1,2)$ because of the effect of the perinatal environment and perinatal morbidity and therapies. It is now well known that LBW is associated with increased cardiovascular disease and hypertension (3-5), diabetes (6), increased blood pressure (BP), and chronic kidney disease (CKD) (7) in adults. This well-documented association between LBW and increased BP or CKD has also been demonstrated in young adults aged 20 (7) and in children aged 5-8 years (8-11) or even younger (12). Though these children are not yet symptomatic of CKD or severe hypertension (HTA), the impact of perinatal imprinting on renal function could be measured early in childhood through close monitoring so as to postpone organ structural alterations and function loss.

Data on renal function alteration due to preterm birth are abundant in the literature. However, renal long-term follow-up is not yet standardized and may fall second to other issues of importance, such as neurodevelopment and lung function.

However, $7 \%$ of births are preterm every year. Hence, it is prudent to determine other factors than gestational age (GA) and birth weight that may impact renal function, to help determine a subsample of children that need to be followed up more closely and/or longer.

Some factors such as growth pattern or diet can be influenced by medical care. This is particularly true for neonatal nutrition. Perinatal nutrition is essential for body and cerebral growth (13-16). Its quality and quantity could, however, and to a certain extent, impair renal function later in life. Indeed, its impact on later renal function has been demonstrated in animal models (17-19) and is now also published in adult humans (20). However, there is no consensus on what the optimal neonatal nutrition should be. The optimal amount of protein intake is particularly discussed (21,22).

In summary, renal function is surely impacted by preterm birth and LBW. It is imperative to determine factors on which physicians may act to postpone the onset of HTA and CKD.

The aims of this study were the following: (i) to longitudinally describe systolic BP (sBP) and renal function in young children born preterm so as to determine when an alteration may be diagnosed; and (ii) to determine which factors in the perinatal period or during childhood were associated with an altered renal function at 5 years of age in preterm-born children, so as to improve monitoring in such children.

\section{METHODS}

\section{Study Type}

We performed a prospective longitudinal SUIVIREIN cohort study in the University Hospital of Nancy, France, with the aim to follow up kidney function in preterm-born children.

\footnotetext{
'Université de Lorraine, EA 4360 APEMAC, Nancy, France; ${ }^{2} \mathrm{CHU}$ Nancy, Neonatal Department, Vandoeuvre-les-Nancy, France; ${ }^{3} \mathrm{CHR}$ Metz-Thionville, Neonatal Department, Thionville, France; ${ }^{4} \mathrm{CHU}$ Nancy, Pediatric Emergency Unit, Vandoeuvre-les-Nancy, France. Correspondence: Rachel Vieux (rvieux@chu-besancon.fr or rvieux.chu@gmail.com) Received 25 October 2016; accepted 28 May 2017; advance online publication 30 August 2017. doi:10.1038/pr.2017.148
} 
The study was approved by the ethics committee and registered with the ClinicalTrials.gov registry, NCT00817921.

\section{Study Population}

All children born preterm at 27-31 weeks of completed gestation and included at birth in the IBUREIN study (23) in the investigator center of Nancy, surviving at discharge, were invited to participate in SUIVIREIN. These children were evaluated at 3, 4 (24), and 5 years. We report the kidney follow-up data from age 3-5 years.

\section{Neonatal Characteristics}

Perinatal medical characteristics. Data were prospectively registered. Antenatal steroid therapy was defined as two doses of bethametasone treatment or more 1-15 days before delivery. Intrauterine growth restriction (IUGR) was defined using Yudkin's curves (25), birth asphyxia as Apgar score $<7$ at $5 \mathrm{~min}$, and bronchopulmonary dysplasia (BPD) as oxygen requirement on day 28.

Neonatal nutrition. Neonatal nutrition was recorded daily from birth to day 28 , with a standardized computerized calculator, taking oral and intravenous nutrition and all medications into account. Total protein intake (grams $/ \mathrm{kg} /$ day) and total caloric intake $(\mathrm{kJ} / \mathrm{kg} /$ day) were, respectively, the sum of protein and calories administrated by the intravenous and oral routes. The ratio of protein to total calories was also analyzed.

Neonatal renal function. Weight and urine output were measured daily. Renal function was further estimated weekly for 1 month by means of the following: blood and urine ionograms; the glomerular filtration rate (GFR) (first estimated on day 2 by means of the Schwartz formula, and then measured with plasma samples); and $12 \mathrm{~h}$ urine collection using the colorimetric method. Tubular function was estimated by sodium fractional excretion measurements (FENa), urine albumin levels, and urine alpha-1-microgobulin levels.

\section{Medical Examination, Renal Biomarkers, and Diet During Follow-up}

General health characteristics. A senior pediatrician examined the children at 3, 4, and 5 years of age. Each child was weighed on a scale with $100 \mathrm{~g}$ precision and measured three times. The final height recorded was measured at least twice. Height and weight were converted to $z$-scores using the WHO child growth standards. The child's medical file was scanned, and illnesses recorded. Parents were questioned for medications either prescribed or purchased over the counter.

Blood pressure. Systolic, mean, and diastolic BP was measured three times in seated children after a 5-min rest. The width of the cuff was $2 / 3$ the arm's length. The device used to measure BP was the Colin Press Mate BP 8800p NIBP Blood Pressure Monitor (COLIN EUROPE, 92400 Courbevoie, France). sBP analyzed was the lowest of the three measures of BP. Blood pressure $z$-scores were calculated using the Classification of hypertension in Children and adolescents, from the Fourth Report on Diagnosis, Evaluation, and Treatment of High blood Pressure in Children and Adolescents. Prehypertension was defined as $\mathrm{sBP} \geq 90$ th percentile, stage 1 hypertension as $\mathrm{sBP}$ from the 95th to 99th percentile plus $5 \mathrm{~mm} \mathrm{Hg}$, and stage 2 hypertension as sBP $>99$ th percentile plus $5 \mathrm{~mm} \mathrm{Hg}$. Percentiles of length used for this classification were calculated thanks to charts from the Centre for Disease Control and Prevention using LMS Box Cox transformation to calculate age- and sex-specific $z$-scores.

Renal function evaluation. Every year (at ages 3, 4, and 5 years), the children were invited to void their bladder into a urine pot. High urine albumin was defined as a urine albumin level $>17.7 \mathrm{mg} / \mathrm{g}$ urine creatinine (26), and high urine beta-2-microglobulin level was defined as $>40.7 \mathrm{mg} / \mathrm{mol}$ (26). Microalbumin was measured with an immunoturbidimetric test. All factors that could affect albuminuria, such as fever, hematuria, urinary tract infection, and long awake periods, were recorded, and in case positive the children were led to collect urine another day when these risk factors of enhanced urine albumin had been treated.

At 5 years, blood was sampled. Plasma ionogram, urea, and creatinine were measured. Creatinine was analyzed with an enzymatic method. The glomerular filtration rate (eGFR) was estimated using the Schwartz formula (27).

Nutrition at 5 years. A questionnaire was administered by a qualified pediatric dietician. It covered all nutritional and hydric intakes over a 3-day period, with two weekdays and a week-end day: Sunday, Monday, and Tuesday. The questionnaire was sent to the preterm-born children's parents, with an explanatory note to fill it in. Questionnaires were returned by the parents in a pre-stamped envelope. Data were verified by the dietitian through a $30 \mathrm{~min}$ phone call to the child's parents. All measures were performed on Géni software, Micro 6, France. The dietitian was blind to the neonatal medical history of the children.

\section{Statistical Analysis}

In bivariate analysis, the association between categorical variables was analyzed using $\chi^{2}$-tests or Fisher exact tests when required; the association between a categorical and a continuous variable was analyzed using the Student's $t$-test or the ranked sum test when required; and the association between two continuous variables was measured using Pearson's correlation coefficient.

Time effect was analyzed with a mixed linear model. Multivariate analysis was performed with a logistic regression model when the dependant variable was categorical and with a linear regression model when the dependant variable was continuous.

Statistical significance was determined at $P<0.05$. All analyses were performed using SAS statistical software, version 9.1 (SAS Institute, Cary, NC).

\section{RESULTS}

\section{Study Population}

One hundred and sixty five children were examined in this follow-up study at ages 3, and/or 4, and/or 5 years; i.e., $69 \%$ of infants were discharged home. Ninety three (56.4\%) children were male. Of the 165 children, 124 had undergone at least two medical exams from years 3-5 in this study. A flow chart is presented in Figure 1.

\section{Medical Data in the Neonatal Period}

General characteristics in the neonatal period. Children were born at (median, IQR) 29 ((refs 32-34)) weeks of gestation, with a birth weight (mean \pm SD) of $1,217 \pm 331 \mathrm{~g}$. The neonatal characteristics of the children included in this study compared with those of children lost to follow-up are presented in Table 1. They did not differ significantly.

Protein intakes in neonates. Protein intakes $(\mathrm{g} / \mathrm{kg} / \mathrm{d})$ were $2.9 \pm 0.6$ on day 7 and $2.8 \pm 0.7$ on day 28 . The protein/calories ratio $(\mathrm{g} / 100 \mathrm{~kJ} / \mathrm{kg} / \mathrm{d})$ was $3.2 \pm 0.6$ on day 7 and $2.7 \pm 0.7$ on day 28 .

Renal function evaluation in the neonatal period. Urine albumin level was significantly lower in boys than in girls (e.g., on day 28, respectively, $6.8(4.3-10.5)$ vs. 11.0 (7.6-16.3), $P=0.0001)$. In multivariate analysis, gender difference persisted $(P=0.04)$ when taking time effect into account $(P=0.08)$. 


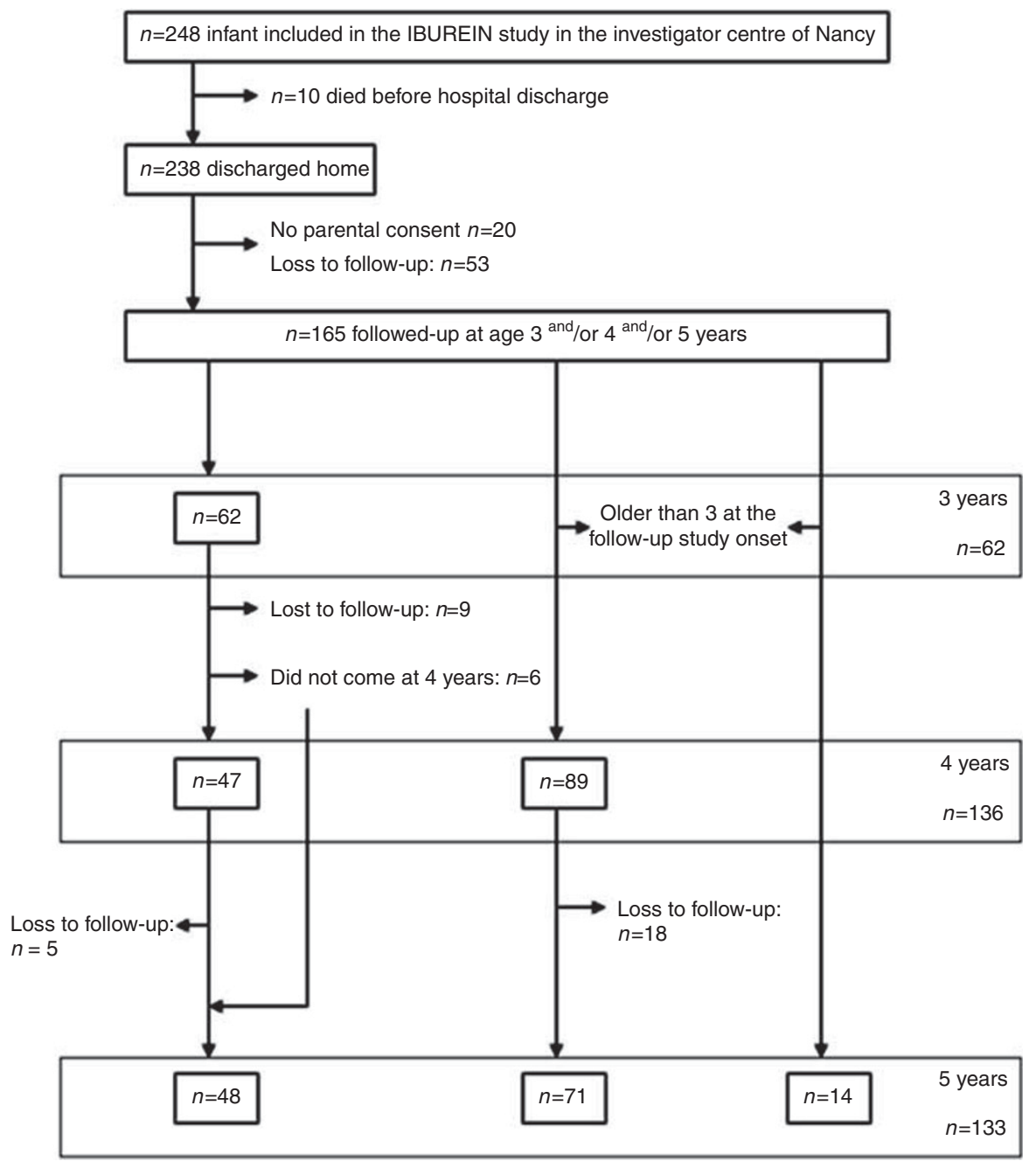

Figure 1. Flow chart of the SUIVIREIN study at the 5-year follow-up.

Table 1. Neonatal characteristics of the children included in the follow-up study

\begin{tabular}{|c|c|c|c|c|}
\hline & & Follo & d/or 4 and/c & \\
\hline & & Yes $(n=165)$ & No $(n=73)$ & $P$ \\
\hline Gender & Male & $93(56.4 \%)$ & $27(62.6 \%)$ & 0.63 \\
\hline Antenatal steroids & Yes & $111(67.3 \%)$ & $40(54.8 \%)$ & 0.06 \\
\hline Intra-uterine growth restriction $<10$ th percentile & Yes & $45(27.3 \%)$ & $12(16.4 \%)$ & 0.07 \\
\hline Hyaline membrane disease & Yes & $93(56.7 \%)$ & $39(53.4 \%)$ & 0.64 \\
\hline Patent ductus arteriosus & Yes & $37(22.4 \%)$ & $10(14.7 \%)$ & 0.18 \\
\hline Bronchopulmonary dysplasia & Yes & $50(30.7 \%)$ & $26(39.4 \%)$ & 0.20 \\
\hline Intraventricular hemorrhage & Yes & $31(18.8 \%)$ & $14(20.6 \%)$ & 0.75 \\
\hline
\end{tabular}

$\mathrm{IQR}$, interquartile range.

All patent ductus arteriosus were treated with ibuprofen. 
Table 2. Renal function in the neonatal period

\begin{tabular}{|c|c|c|c|c|c|}
\hline & Day 7 & Day 14 & Day 21 & Day 28 & $P$ \\
\hline Plasma creatinine, $\mu \mathrm{mol} / \mathrm{l}$ & $63.045 .0-77.0)$ & $56.5(46.5-65.0)$ & $51.0(40.0-61.0)$ & $48.0(39.0-57.0)$ & $<0.0001$ \\
\hline Creatinine clearance, $\mathrm{ml} / \mathrm{min} / 1.73 \mathrm{~m}^{2}$ & $15.9(12.2-24.0)$ & $18.3(14.0-23.0)$ & $19.2(14.3-27.3)$ & $21.7(15.6-29.9)$ & $<0.0001$ \\
\hline Fractional excretion of sodium, \% & $2.1(1.2-3.2)$ & $1.0(0.6-2.1)$ & $0.7(0.3-1.6)$ & $0.6(0.3-1.2)$ & $<0.0001$ \\
\hline Urine albumin level, $\mathrm{mg} / \mathrm{mmol}$ & $11.9(7.1-20.7)$ & $12.1(8.0-19.3)$ & $10.2(6.1-16.2)$ & $8.4(5.4-13.6)$ & 0.10 \\
\hline Urine alpha-1-globulin level, mg/mol & $49.8(29.8-81.1)$ & $48.7(25.1-80.0)$ & $29.2(18.3-57.3)$ & $21.8(15.8-37.4)$ & $<0.0001$ \\
\hline
\end{tabular}

Urine albumin level, albuminuria/urine creatinine; urine alpha-1-globulin level, alpha-1-globulinuria/urine creatinine.

Results are median, interquartile range. $P$ tests the time effect from day 7 to day 28.

Table 3. Anthropometric measures collected at the medical follow-up exams

\begin{tabular}{lccc}
\hline & 3 Years & 4 Years & 5 Years \\
\hline \multicolumn{4}{l}{ Weight z-score } \\
All & $-0.9(-0.9 ; 0.3)^{\mathrm{a}}$ & $-0.3(-0.9 ; 0.2)^{\mathrm{b}}$ & $-0.1(-0.8 ; 0.4)^{\mathrm{c}}$ \\
Boys & $-0.1(-1.1 ; 0.4)^{\mathrm{a}}$ & $-0.1(-1.2 ; 0.2)^{\mathrm{b}}$ & $0.2(-0.7 ; 0.4)^{\mathrm{c}, \mathrm{d}}$ \\
Girls & $-0.9(-0.9 ;-0.7)^{\mathrm{a}}$ & $-0.6(-0.7 ; 0.1)^{\mathrm{b}}$ & $-0.8(-0.9 ; 0.1)^{\mathrm{c}}$
\end{tabular}

4 , and $15.2 \pm 1.5 \mathrm{~kg} / \mathrm{m}^{2}$ at 5 years. There was a gender effect on absolute $\mathrm{z}$-score difference at each examination for weight and height parameters, but not for BMI. Other details are presented in Table 3.

Blood pressure from ages 3 to 5 years. There was no gender effect on prehypertension, nor on stages 1 and 2 hypertension. Sixty two percent of children with HTA at 5 years had HTA or prehypertension at 3 or 4 years.

Urine albumin level from ages 3 to 5 years. High urine albumin level was observed in $11 \%$ of 3 -year-old children, in $13 \%$ of 4 -year-olds, and in $14 \%$ of 5 -year-olds. There was no time effect from years 3 to 5 on urine albumin levels.

High albuminuria level at 3 or 4 years was not associated with high albuminuria level at 5 years.

\section{Data Recorded at 5-Year Follow-up}

Renal function. eGFR was $113(100 ; 131) \mathrm{ml} / \mathrm{min} / 1.73 \mathrm{~m}^{2}$. No child had renal insufficiency. eGFR was significantly lower in boys than in girls: $109(99 ; 123) \mathrm{ml} / \mathrm{min} / 1.73 \mathrm{~m}^{2}$ vs. 122 $(101 ; 140)$, respectively $(P=0.03)$. Urine beta-2-microglobulin level was $10.6(8.3 ; 13.6) \mu \mathrm{g} / \mathrm{mmol}$ in boys and $9.6(7.2 ; 14.2) \mu \mathrm{g} /$ mmol in girls $(P=0.17)$.

Nutrition. Energy intake was (median, range) 1,739 $(1,493 ; 1,946) \mathrm{kCal} / \mathrm{d}$ (recommended: 1,362-1,434). Protein intake was $17 \%$ of total energy, fat intake was $36 \%$, and carbohydrate intake was $46 \%$ (recommended: $10 \%, 40 \%$, and $50 \%$, respectively).

\section{Factors Associated with Blood Pressure and Renal Function at 5 Years}

Blood pressure. sBP at 5 years was neither associated with protein intake on day 7 nor with protein/calories ratio during the first week of life. sBP was significantly correlated with protein intake on day $28(R=0.21, P=0.03)$, meaning $5 \%$ of sBP variability at 5 years may be explained by the protein intake on day 28. sBP was not significantly associated with current protein, fat, or carbohydrate diets, nor with current water and salt intakes (data not shown).

Systolic blood pressure at 5 years was significantly correlated with BMI at 4 and 5 years $(R=0.29, P=0.002$, at 4 years; and $R=0.33, P=0.005$, at 5 years). 
In bivariate analysis, prehypertension or stages 1 and 2 hypertension at 5 years were significantly associated with steroids and hyaline membrane disease. In multiple linear regression modeling, sBP at 5 years as a continuous variable showed a significant association with protein intake on day 28 of life $(\beta=2.1 \pm 1.0, P=0.03)$. In other words, after adjustment for current BMI, gender, and antenatal steroid use, sBP at 5 years increased by $2.1 \pm 1.0 \mathrm{~mm} \mathrm{Hg}$ for each $\mathrm{g} / \mathrm{kg}$ increase in protein diet on day 28 .

Urine albumin level. Overall, $21 \%$ of children with high albumin had sBP $\geq 90$ th percentile vs. $10 \%$ with $\mathrm{sBP}<90$ th percentile $(P=0.24)$. Urine albumin at 5 years was not associated with neonatal data or nutrition at 5 years, nor with growth pattern.

Estimated GFR. eGFR was not associated with current height $(R=0.14, \quad P=0.28)$, weight $(R=0.08, \quad P=0.54)$, or BMI $(R=0.01, P=0.95)$. It was not associated with nutrition in the neonatal period or at 5 years. Neonatal factors such as hyaline membrane disease and necrotising enterocolitis were significantly associated with a decreased eGFR at 5 years in the bivariate analysis $\left(113 \pm 23\right.$ vs. $124 \pm 27 \mathrm{ml} / \mathrm{min} / 1.73 \mathrm{~m}^{2}$, $P=0.002$, and $104 \pm 18$ vs. $119 \pm 25, P=0.01$, respectively). This association persisted in multiple regression analysis after adjusting for gender.

\section{DISCUSSION}

No preterm-born child of our study population had renal insufficiency at the end of the neonatal period. Yet risk factors of CKD were latent, such as IUGR and incomplete antenatal steroid use. Most of the 5-year-old children had caught-up BMI, and a few had high albuminuria levels. However, an asymptomatic danger still lurked: $10 \%$ of 5 -year-old children had prehypertension. Increased sBP may be one of the first detectable signs of perinatal imprinting on renal function. This increased sBP in preterm-born and LBW subjects was first described in the 1980s and was more recently reviewed (28) by pointing out an increase in rest sBP from 2.5 to $3.8 \mathrm{~mm} \mathrm{Hg}$ in 18-year-old subjects. This was also described in children aged $8-11$ years $(9,11)$ and recently in younger children aged 2-3 years (12). Our results confirm that high sBP levels may be seen in early childhood, although most preterm-born children are not yet hypertensive.

In such a context of preterm birth, many families and doctors are prone to seeing these children quickly catching up weight. Because of their anxiety, mothers tend to overfeed their preterm-born infant. Yet, studies have established a relationship between catch-up growth and later renal function. Indeed, Eriksson et al. (29) published that LBW associated with a rapid weight catch-up or no catch-up during childhood significantly increased the risk for HTA. Others determined a significant association between HTA at age 21 years and rapid height catch-up from years 1-21 or weight catch-up from years 2-21 (ref. 6). The adverse effect of promoting faster weight gain in infants born small for gestational age (SGA) has been investigated in a randomized trial assigning SGA infants to a standard diet or to a nutrientenriched formula (28\% more protein). After adjusting for age, sex, BMI $z$-score, and social class, diastolic and mean BP were significantly lower in children aged 6-8 enrolled in the standard formula group, with a mean difference of $3 \mathrm{~mm} \mathrm{Hg}$ (30). Similar results were measured but only in girls when diet was enriched with long-chain polyunsaturated fatty acids. Girls who had received such an enriched diet had higher adiposity and BP at ages 9-11 (ref. 31). Duncan AF determined a gender-specific relationship between infant growth and sBP with a higher sBP in 1-3-year-old girls who had higher adiposity compared with boys (12).

Our results state that higher neonatal protein intakes could be associated with an increased sBP at 5 years. This point is to be highlighted, because nutrition is one of the sole neonatal factors on which physicians may have a direct impact. A consensus on the most appropriate neonatal nutrition does not exist. The most optimum amount of protein intake is still being debated among physicians working in the era of neonatal medicine. High protein intakes are associated with poor renal outcome as they trigger hyperfiltration (19) possibly creating glomerular hypertension in an oligonephronic kidney. Restricted protein diet was associated with significantly decreased proteinuria and with a decline in eGFR in adult patients (32). Dietary protein restriction has also proven its efficacy in postponing the progression of advanced (33) and moderate (34) renal disease in adults though not in children in whom a low-protein diet for 3 years did not seem to decrease renal function in children with CRF. However, such dietary data must be taken with caution in perinatal medicine. Preterm-born children must continue their organ development and body growth in the context of increased energy loss due to thermal homeostasis, breathing, digestion, and other challenges that present during extra-uterine life. Many preterm-born children suffer from extra-uterine growth restriction $(15,35,36)$ that may impair their neurocognitive development $(13,15)$. Thus, $4 \mathrm{~g} / \mathrm{kg} / \mathrm{d}$ proteins is recommended after the first days of life for preterm-born children (37). Such a quantity of protein intake is not easy to reach within the first days of life, at a time when fluid intakes need to be controlled to prevent PDA. However, if enteral protein intake in the first two weeks of life was positively associated with neurodevelopmental outcome (15), an increased protein intake in the first week of life had no effect on growth and clinical outcome or on neurodevelopment at 18 months (16). This suggests that the timing of protein intake could be as important as its quantity. In our study, sBP was not correlated to protein intake on day 7 , but at the end of the neonatal period. This should be confirmed in further studies, but renal tolerance to protein intakes could depend on the amount received in the first postnatal weeks, and on postnatatal age.

Antenatal steroids also decreased the risk for prehypertension at 5 years. Increased sBP may trigger glomerulosclerosis by increasing the pressure in the glomerular capillaries, hence aggravating reduced nephron number due to LBW (7). 
Moreover, in preterm-born children, the risk for glomerulosclerosis may also be due to other factors such as vascular remodeling with arterial stiffness, endothelial dysfunction, and narrowing of small arteries (38). Such vascular remodeling can impact vascular resistance and BP. Accordingly, association between BP and GFR is most important and was pointed out as explaining a large part of the decline in GFR (23).

Last but not the least, albuminuria is used in many crosssectional studies to measure the impact of LBW or preterm birth on renal function. Surely this urine biomarker is largely used in pediatric nephrology to measure the progression of CKD, but to our knowledge it has not been validated in preterm-born children with specific architectural kidney changes. This longitudinal study showed that the albuminuria level measured under the same conditions in the same children at different ages was fluctuating a lot. This questions its validity in the follow-up of renal function in LBW subjects.

The strength of this study lies in it having a prospective record of neonatal nutrition and morbidities and of renal function both in the neonatal period and longitudinally in children aged 3-5 years. Adjusting on current nutrition helps to argue that the impact of neonatal protein intake on sBP at 5 years is not biased by the current protein intake. Noteworthy, for BP measures in childhood, we chose a cuff by two-thirds upper-arm circumference, which may underestimate systolic and diastolic BP (39). However, this measure bias was nondifferential and could not influence the differences measured between groups. Nomograms used to define hypertension were those from the States. Indeed, French nomograms are now quite old. This may have overestimated the prevalence of hypertension as published for an Italian population (40). We also lack data on nutrition at 36 weeks' postnatal age. Moreover, $40 \%$ of the cohort was lost to follow-up, inducing a loss in power. Nevertheless, this is an interesting longitudinal cohort. These results need to be confirmed in further controlled trials randomizing neonatal nutrition patterns.

\section{Conclusion}

Increase in protein intake at the end of the neonatal period was associated with increased sBP at 5 years of age in preterm-born children. Surely early protein intake is essential for neurodevelopment; however, a too high intake could induce hyperfiltration, increasing sBP before 5 years of age in preterm-born children.

Disclosure: The authors declare no conflict of interest.

\section{REFERENCES}

1. Ness RB, Catov J. Invited commentary: timing and types of cardiovascular risk factors in relation to offspring birth weight. Am J Epidemiol 2007;166:1365-7.

2. Barker DJP Mothers, Babies and Disease in Later Life. London, UK: BMJ Publishing Group, 1994.

3. Barker DJP. Fetal origins of coronary heart disease. BMJ 1995;311:171-5.

4. Law CM, de Swiet M, Osmond C, et al. Initiation of hypertension in utero and its amplification throughout life. BMJ 1993;306:24-7.
5. Curhan GC, Willett WC, Rimm EB, Spiegelman D, Ascherio AL, Stampfer MJ. Birth weight and adult hypertension, diabetes mellitus, and obesity in US men. Circulation 1996;94:3246-50.

6. Rotteveel J, van Weissenbruch MM, Twisk JW, Delemarre-Van de Waal HA. Infant and childhood growth patterns, insulin sensitivity, and blood pressure in prematurely born young adults. Pediatrics 1998;122:313-21.

7. Keijzer-Veen MG, Finken MJ, Nauta J, et al. Is blood pressure increased 19 years after intrauterine growth restriction and preterm birth? A prospective follow-up study in The Netherlands. Pediatrics 2005;116: $725-31$.

8. Strufaldi MW, Silva EM, Franco MC, Puccini RF. Blood pressure levels in childhood: probing the relative importance of birth weight and current size. Eur J Pediatr 2009;168:619-24.

9. Whincup P, Cook D, Papacosta O, Walker M. Birth weight and blood pressure: cross sectional and longitudinal relations in childhood. BMJ 1995;311:773-6.

10. Taylor SJ, Whincup PH, Cook DG, Papacosta O, Walker M. Size at birth and blood pressure: cross sectional study in 8-11 year old children. BMJ 1997;314:475-80.

11. Bacchetta J, Harambat J, Dubourg L, et al. Both extrauterine and intrauterine growth restriction impair renal function in children born very preterm. Kidney Int 2009;76:445-52.

12. Duncan AF, Heyne RJ, Morgan JS, Ahmad N, Rosenfeld CR. Elevated systolic blood pressure in preterm very-low-birth-weight infants $\leq 3$ years of life. Pediatr Nephrol 2011;26:1115-21.

13. Lucas A, Morley R, Cole TJ, et al. Early diet in preterm babies and developmental status in infancy. Arch Dis Child 1989;64:1570-8.

14. Lucas A, Morley R, Cole TJ. Randomised trial of early diet in preterm babies and later intelligence quotient. BMJ 1998;317:1481-7.

15. Ehrenkranz RA, Dusick AM, Vohr BR, Wright LL, Wrage LA, Poole WK. Growth in the neonatal intensive care unit influences neurodevelopmental and growth outcomes of extremely low birth weight infants. Pediatrics 2006;117:1253-61.

16. Cormack BE, Bloomfield FH, Dezoete A, Kuschel CA. Does more protein in the first week of life change outcomes for very low birthweight babies? J Paediatr Child Health 2011;47:898-903.

17. Schreuder MF, Nyengaard JR, Remmers F, An Wijk JA, Delemarre-van de Waal HA. Postnatal food restriction in the rat as a model for a low nephron endowment. Am J Physiol Renal Physiol 2006;291:F1104-7.

18. Wlodek ME, Mibus A, Tan A, Siebel AL, Owens JA, Moritz KM. Normal lactational environment restores nephron endowment and prevents hypertension after placental restriction in the rat. J Am Soc Nephrol 2007;18:1688-96.

19. Boubred F, Buffat C, Feuerstein JM, et al. Effects of early postnatal hypernutrition on nephron number and long-term renal function and structure in rats. Am J Physiol Renal Physiol 2007;293:F1944-9.

20. Chauveau P, Combe C, Rigalleau V, Vendrely B, Aparicio M. Restricted protein diet is associated with decrease in proteinuria: consequences on the progression of renal failure. J Ren Nutr 2007;17:250-7.

21. Poindexter BB, Langer JC, Dusick AM, Ehrenkranz RA. National Institute of Child Health and Human Development Neonatal Research Network. Early provision of parenteral amino acids in extremely low birth weight infants: relation to growth and neurodevelopmental outcome. J Pediatr 2006;148:300-5.

22. Blanco CL, Gong A, Liechty EA. Plasma Amino Acid Concentrations in ELBW Infants During 1st Week of Life Correlate Inversely with 18 Month. Bayley MDI Pediatric Academic Societies Conference, volume E-PAS2009:2155.3. Baltimore, MD, 2009.

23. Vieux R, Hascoet JM, Merdariu D, Fresson J, Guillemin F. Glomerular filtration rate reference values in very preterm infants. Pediatrics 2010;125:e1186-92.

24. Vieux R, Hascoët JM, Franck P, Guillemin F. Increased albuminuria in 4-year-old preterm-born children with normal height. J Pediatr 2012;160: 923-8. 
25. Yudkin PL, Aboualfa M, Eyre JA, Redman CW, Wilkinson AR. New birthweight and head circumference centiles for gestational ages 24 to 42 weeks. Early Hum Dev 1987;15:45-52.

26. European Society for Paediatric Nephrology. ESPN Handbook. Lyon: Medcom, 2002.

27. De Souza V, Rabilloud M, Cochat P, et al. Schwartz formula: is one K coefficient enough for all children? PLoS ONE 2012;7:e53439.

28. de Jong F, Monuteaux MC, van Elburg RM, Gillman MW, Belfort MB. Systematic review and meta-analysis of preterm birth and later systolic blood pressure. Hypertension 2012;59:226-34.

29. Eriksson JG, Forsén T, Tuomilehto J, Osmond C, Barker DJ. Early growth and coronary heart disease in later life: longitudinal study. BMJ 2001;322: 949-53.

30. Singhal A, Cole TJ, Fewtrell M, et al. Promotion of faster weight gain in infants born small for gestational age: is there an adverse effect on later blood pressure? Circulation 2007;115:213-0.

31. Kennedy K, Ross S, Isaacs EB, et al. The 10-year follow-up of a randomised trial of long-chain polyunsaturated fatty acid supplementation in preterm infants: effects on growth and blood pressure. Arch Dis Child 2010;95:588-95.

32. Levey AS, Adler S, Caggiula AW, et al. Effects of dietary protein restriction on the progression of advanced renal disease in the Modification of Diet in Renal Disease Study. Am J Kidney Dis 1996;27: 652-3.

33. Klahr S, Levey AS, Beck GJ, et al. Effects of dietary protein restriction on the progression of moderate renal disease in the Modification of Diet in Renal Disease Study Group. N Engl J Med 1994;330:877-4.
34. Wingen AM, Fabian-Bach C, Schaefer F, Mehls O. Randomised multicentre study of a low-protein diet on the progression of chronic renal failure in children. European Study Group of Nutritional Treatment of Chronic Renal Failure in Childhood. Lancet 1997;349:1117-23.

35. Lemons JA, Bauer CR, Oh W, et al. Very low birth weight outcomes of the National Institute of Child Health And Human Development Neonatal Research Network, January 1995 through December 1996. NICHD Neonatal Research Network. Pediatrics 2001;107:E1.

36. Clark RH, Thomas P, Peabody J. Extrauterine growth restriction remains a serious problem in prematurely born neonates. Pediatrics 2003;111: 986-0.

37. Agostoni C, Buonocore G, Carnielli VP, et al. ESPGHAN Committee on Nutrition. Enteral nutrient supply for preterm infants: commentary from the European Society of Paediatric Gastroenterology, Hepatology and Nutrition Committee on Nutrition. J Pediatr Gastroenterol Nutr 2010;50: 85-91.

38. Ligi I, Grandvuillemin I, Andres V, Dignat-George F, Simeoni U. Low birth weight infants and the developmental programming of hypertension: a focus on vascular factors. Semin Perinatol 2010;34:188-92.

39. Clark JA, Lieh-Lai MW, Sarnaik A, Mattoo TK. Discrepancies between direct and indirect blood pressure measurements using various recommendations for arm cuff selection. Pediatrics 2002;110:920-3.

40. Marras AR, Bassareo PP, Ruscazio M. The prevalence of paediatric hypertension, emphasising the need to use specific population references: the Sardinian Hypertensive Adolescents Research Programme Study. Cardiol Young 2009;19:233-8. 